\title{
Transformation of Academic Ecology through Information Communication Technology Adoption
}

\author{
Divya Dosaya, Tanu Shukla, and V. S. Nirban
}

\begin{abstract}
The role of technology in evolving and uplifting the lifestyle of populations worldwide has been enormous since the advent of 21st Century. Education when combined with technology, escalates the whole process of growth and development by making the user more and more independent in managing complex tasks in real time with less effort. This is an integrated process involving many factors to interplay. Acceptance of technology in the field of education still remains a challenge. There exist discrepancies in access and acceptance of technology among users in the academic realm, especially in the developing countries. This study attempts to gauge such discrepancies and the factors that lead to them by digging into the attitudes that urge people to accept or reject the Learning Management System (LMS) - a widely used technological intervention in the teaching learning process. The study was conducted in an engineering institute in India and data was collected from both the students and the teachers. The factors identified by the Unified Theory of Acceptance and Use of Technology (UTAUT) Model were used to design tools for data collection. Interviews were also conducted to substantiate the quantitative findings. The results indicated that acceptance of LMS was less in women as compared to their male counterparts both among the teachers and the students. The dependency on technology is influenced by factors such as the extent to which the user considers it easy to operate and, social influence from colleagues and seniors. Thus, it becomes clear that Effort Expectancy and Social Influence play an important role in the acceptance or rejection of available technology aides in education among women.
\end{abstract}

Index Terms-Learning management system, UTAUT model, learning management system, gender, effort expectancy, social influence.

\section{INTRODUCTION}

The world has entered into an era where information technology is central to economy, education, work and cultures across the globe. Thus, with the advent of the information age, an information society is at hand [1]. ICT reforms have given rise to 'learning economy' wherin the capability to learn and create new knowledge; adapt to changing conditions determines the performance of individuals, institutions, regions, and countries [2]. It is quite evident that governments across the globe don't want to be left out of the opportunities created by the information society. Before planning to proceed and develop strategies for forming an information society, it is crucial to investigate that whether this actually helps in the development of the society or rather proves an interruption in doing so.

Manuscript received October 9, 2019; revised March 24, 2020

Divya Dosaya and V. S. Nirban are with the BITS Pilani, India (e-mail: divyadosaya@gmail.com).

Tanu Shukla was with BITS Pilani, India.
Research in technology adoption has reached its most advanced stage. With the rapid escalation of technology innovations in every domain, technology adoption-related issues have gained increasing prominence in recent times. Web -based learning management systems provide an open learning environment to students, which is not restricted by the boundaries of time and place and also increases users' performance and productivity [3]. In order to enhance usage of such platforms it is necessary to identify the factors that inspires students to use adopt them [4]. Organizations and governments are putting in large scale efforts to introduce new technologies and facilitate a paradigm shift in the lifestyle of the users. Such efforts remain futile unless these innovations are adopted by the people. It is a recognized fact that unless the individual factors affecting teachers' and students' adoption patterns are studied, the potential of learning through technological interventions will not be fully utilized, thus lowering the return on the investment [5]. Innovations like Cloud Computing [6] and e Governance [7] seemed to offer promising advantages, but still they have not by far been adopted by the users as expected.

\section{LiteratURE REVIEW}

Adoption of e-learning platforms for enhanced educational outcome has been an integral part of policy planning. The current scenario shows increase in the interest of decision makers towards inclusion of ICT innovation in education. Government of India has launched various state and national level programs along with certain privately led initiatives with a common goal of transforming education dissemination both at the school and the higher education levels. Technology can also be considered as a useful resort due to its far reaching effects and cost effectiveness. Manu universities have integrated tools emerging from information technology. The acceptance behaviors of users vary significantly across gender, area (rural and urban institutes), disciplines, etc. Most of the higher education institutes in India offer online courses. The management and dissemination of these courses requires an online platform where everything can be done through the internet. Learning Management System (LMS) is one such platform which supports instructors to manage the courses online. It is an ICT tool which was designed to make student-teacher transactions smoother and efficient.

Learning Management Systems have proved to be an excellent forum for facilitating online learning. They are flexible and easy to create and maintain; they encourage communication and information exchange therefore promoting an interactive and engaging environment and the 
contents shared are threaded and can be retrieved anywhere and at anytime. Studies have also observed that LMS plays an important role as a supplementary platform in language learning [8]. Despite governments and school authorities spending a large chunk of funds in equipping classrooms with technology, there can be seen a varied pattern of usage among the teachers and the students.

Technology is the knowledge/information that permits some tasks to be accomplished more easily, some service to be rendered or the manufacture of a product [9]. It assists the applicant to do work easier than he would have in the absence of the technology; hence it helps save time and labor [10]. Adoption, on the other hand, as defined by Loevinsohn et al., 2013 [11], as the integration of a new technology into existing practice and is usually preceded by a period of 'trying' and some degree of adaptation. An individual's continuous use of technology allows them to practice and reuse it habitually thereby building a positive perception about technology [12]. Studies have extensively discussed the relationship between habit and technology adoption [13], [14]. Researchers have often conceptualized hedonic motivation as perceived enjoyment and have also discussed its relationship with technology acceptance and usage [15], [16]. Adoption is a mental process in which an individual pass from first hearing about an innovation to the final utilization of it [17]. Adoption can be understood in two ways, first, the rate of adoption or the relative speed with which users adopt an innovation and intensity of adoption or the level of use of a given technology in any time period [7]. The degree of inclusion of technology in teaching methods by the faculties in higher education institutes is influenced by a number of factors. Literature suggests that technology adoption is not related to the aspects of technology alone, but has evolved as a much more complex process involving the dimensions of user attitude and personality [6], social influence [18], trust [19] and numerous facilitating conditions. Studies related to technology adoption aimed to understand, predict, and explain the variables influencing adoption behavior at the individual as well as organizational levels to accept and use technological innovations. These studies have led to the development of conceptual models and frameworks to understand the relationship of these variables with the adoption behavior [20]. One such model is the UTAUT Model (as shown in Figure 1) coined by Venkatesh et. al (2003) [21] which explained that performance expectancy [22]-[24], effort expectancy [25], [26], social influence [27] and facilitating conditions [28] play an important role in predicting behavioral intention to use a particular technology [29]-[31]. With an increase in the values of the four constructs, there is a simultaneous increase in the behavioral intention to use the technology which determines the users' acceptance or rejection of the technology. The model has been extensively used to study technology adoption behavior of people across sectors. In the educational sector the UTAUT Model has provided important insights with respect to integration of various new technologies in the teaching learning process for instance use of interactive whiteboards [32], [33], m-Learning [34]-[38].

Performance Expectancy or perceived usefulness is the belief of an individual that using a particular technology will help users in bettering their performance and further increase the quality of their work. Across cultures, performance expectancy has been found to be a prominent indicator of technology acceptance whereas social influence is more important for the East than the West [39], [40]. Sumak et. al., (2010) [50] found a significant and direct effect of performance expectancy in influencing behavioral intention to use Moodle. Performance expectancy also influences the choice of using tablet PCs [41].Performance Expectancy is found to be the strongest indicator of behavioral intentions in both voluntary and mandatory settings [42]. Rewarding employees on using ICT tools in their roles has positive moderating effect on their acceptance behavior [43]. Also the more interactive the ICT tool is the more easily it gets accepted by the intended user [44].

Effort Expectancy can be defined as the perceived ease with which the user can work with a technological tool in combination with their regular work processes [21]. Perceived ease of use, ease of learning and efficacy beliefs are important factors that are believed to influence effort expectancy and behavioral intention [45]. Research has also observed significant relationship between effort expectancy and usage of e-governance technology [46]. Effort expectancy has also been observed to play a crucial role in the acceptance of LMS amongst pre-school teachers [47].

Social Influence refers to the degree, other users' behavior towards a system, play a role in an individuals' acceptance of a system. Social Influence has been an interest particularly in the Asian and African research pertaining to the cultural factors that explain the phenomenon that determine the intention to use technology [48], [49]. Al Shafi et. al., 2009 [50], found that peers beliefs play a role in motivating people to use e-government services. Fidani \& Idrizi (2012) [2] also observed the influence of colleagues on behavioral intentions to adopt or reject a technological intervention. Social Influence along with Social Image have also been found to influence acceptance behavior [51].

Facilitating Conditions refers to the extent to which the organization in which the individual works has all the required support and infrastructure to promote the adoption of a system or technology. Conditions like lack of assistance, timely support, incomplete information and limited resources have proven to be a hindrance in the acceptance of web based technology among students [52]. Students need technical assistance along with teachers' support in order to facilitate their LMS usage [53]. Liu \& Wang (2009) [54], reported that usage rates, time spent on use and confidence with which one uses the computers are some of the facilitating conditions that positively influence technology acceptance behavior. Providing the equipments alone does not solve the purpose of creating conducive environments for technology learning and acceptance but it is the attitudinal and personality factors of the teacher, training and experience they posses that matters more and further develops technology anxiety [42], [55].

\section{THEORETICAL FRAMEWORK}

A plethora of studies have attempted to trace the reasons behind the acceptance or rejection of a particular technology 
intervention, each of them testing different factors that play a role. These studies included the TRA [43], [44]; the TAM [45]-[47]; the TPB [48], [49]; a combination of TAP and TPB Models [50]; the MPCU Model [51]; the MM Model [52]; the SCT Model [53]; IDT [54].

Venkatesh et al., in 2003 [31], studied all the existing models of technology adoption and synthesized the UTAUT Model. They studied the already existing models and theories which led to the formation of the Unified Theory of Acceptance and Use of Technology (UTAUT) model of technology acceptance. The UTAUT has four predictors of users' behavioral intention which are performance expectancy, effort expectancy, social influence and facilitating conditions. The UTAUT Model has been tested in a variety of spheres across a number of countries around the world. The applicability of the UTAUT was checked in the starkly different cultural context of China and U.S. where it was found that culture plays an important role in adoption of technology. On a similar ground, another research in Korea reinstated the importance of culture [55].

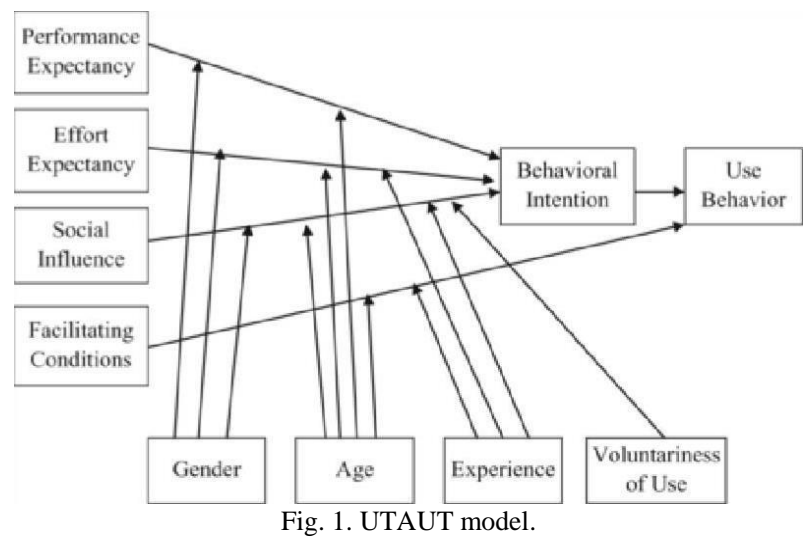

Since its inception, the UTAUT Model has formed the basis of a large number of studies on technology adoption in various kinds of organizations. This paper attempts to trace the differences in technology acceptance behavior exhibited by male and female users in an academic institute by the means of four predictors indicated by this model. The objectives of the study are:

- Addressing the gender gap in acceptance of technology in higher education institutions.

- Explore the factors that contribute in such discrepancy by studying the users' attitudes towards Learning Management Systems (LMS) in an engineering institute in India.

\section{Methodology}

The study is based on the use of Learning Management System by the students and staff of an engineering institute in the state of Rajasthan, India. As soon as the students are registered in the institute, they are encouraged to use the Learning Management System. At the same time, the faculty members are also responsible to keep the system updated regularly so that the platform remains an effective medium of information sharing and communication between the teacher and the student. A mixed method approach was used to conduct the study where the data were collected both by questionnaire and semi structured interviews [56]-[58]. The sample was randomly drawn for data collection, which consisted of hundred engineering students and staff members comprising 56 male and 44 female respondents. Sequential explanatory design was used to carry out the research. Quantitative data from hundred faculty members of the engineering institute was collected for quantitative analysis. The questionnaire comprised of items on a five-point Likert scale which were based on the dimensions of UTAUT Model, namely, performance expectancy, effort expectancy, social influence and facilitating conditions. The data acquired was found to be normally distributed and the Cronbach Alpha value (internal consistency) was found to be good; i.e. .83 [59]. Further, t-test was used to measure the dimension wise difference in technology acceptance behavior among male and female faculty members. Qualitative analysis involved semi structured interviews of 20 students, out of which $60 \%$ were men and $40 \%$ were women. The objective of the interviews was to explore if technology adaption gaps existed among the students as well across gender and the factors that were responsible for this gap.

\section{RESUlTS AND DisCUSSION}

The scores of male and female participants were obtained based on the dimensions of performance expectancy, effort expectancy, facilitating conditions and social influence. The difference between the scores of male and female participants on each dimension was estimated using the t-test.

Performance Expectancy can be described as the extent to which an individual think that using a particular technology will help them in enhancing their job performance. In Table I, the difference in the scores of the male and female participants in the institute clarifies that in order to perform better men are more likely to adopt technology than women. Interviews also revealed that women were less concerned about using technology for better task performance rather they looked for alternatives. For example, a female student reported that although LMS was useful, but she still preferred class notes over slides. The findings of the study are consistent with the findings of El-Gayar et al. [60] who observed that the acceptance of Electronic Document Management System (EDMS) at the Portuguese City Council was more in the male employees than the female employees. It explains the fact that students use LMS if they believe that using it as a part of their study courses will help them in their academic performance [61].

\begin{tabular}{lllll}
\multicolumn{5}{c}{ TABLE I: PERFORMANCE EXPECTANCY } \\
\hline Gender & $\mathrm{N}$ & Mean & SD & t-value \\
\hline Male & 56 & 143 & 24 & \multirow{2}{*}{$2.4 * *$} \\
Female & 44 & 131 & 17 & \\
\hline$* * p<0.01$ & & & &
\end{tabular}

Effort expectancy is the degree of ease with which the user can use the technology. Table II, suggests that women are more likely to use a technology depending upon the ease with which it can be used. It is less probable that female users would use a complex technology; they require it to be simple and easy, whereas male users are quite flexible and are ready to adopt complex technologies to make work easy and 
smooth.

TABLE II: EFFORT EXPECTANCY

\begin{tabular}{lllrl}
\multicolumn{5}{c}{ TABLE II: EFFORT EXPECTANCY } \\
\hline Gender & $\mathrm{N}$ & Mean & SD & t-value \\
\hline Male & 56 & 133 & 7.9 & \multirow{2}{*}{$2.5^{* *}$} \\
Female & 44 & 149 & 16.1 & \\
\hline$* * p<0.01$ & & & &
\end{tabular}

Social Influence is the extent to which technology usage is determined by what the other important people think about its acceptance and rejection. Table III specifies that social influence plays a large role in the acceptance or rejection of a technology among women users than their male counterparts. Social approval of technology and its usage by important colleagues and seniors matters differently for women and men. Similarly, Sumak et al., (2010) [62] found that social influence contributes the maximum to the acceptance behaviors of students in the higher education institutes.

TABLE III: SOCIAL INFLUENCE

\begin{tabular}{|l|l|l|l|l|}
\hline Gender & $\mathrm{N}$ & Mean & SD & \multirow{2}{*}{ t-value } \\
\hline Male & 56 & 129 & 11 & \multirow{2}{*}{$2.2 * *$} \\
\hline Female & 44 & 138 & 25 & \\
\hline \multirow{2}{*}{$* *^{*}<0.01$} &
\end{tabular}

Facilitating conditions is the extent to which an individual believes that an organization and technical infrastructure exists to support the adoption and use of the technology. Table IV portrays that there exists no significant difference between the technology acceptance behavior of male and female users owing to the existing facilitating conditions in the organization. Studies also exhibit that facilitating conditions don't have a major role to play in technological acceptance in the higher education institutes [63].

\begin{tabular}{lllll}
\multicolumn{5}{c}{ TABLE IV: FACILITATING CONDITIONS } \\
\hline Gender & $\mathrm{N}$ & Mean & SD & t-value \\
\hline Male & 56 & 151 & 18.3 & \multirow{2}{*}{1.5} \\
Female & 44 & 137 & 30.5 & \\
\hline$* * p<0.01$ & & &
\end{tabular}

The focus of the study was to magnify the differences in the technology acceptance behavior of men and women. The result point out that male users' intention to use an ICT tool in the academic settings depends largely on whether the usage will add in their work performance, whereas, with women users along with the effect of the use of technology on work, the ease with which the technology can be used and also influence of peer and seniors with respect to the usage, also plays a large role.

\section{CONCLUSION}

Technology intervention does transform the workplace. Academic organizations are no exception to such transformation. The influence of gender on adoption of technology can be clearly seen. The factors marked by the UTAUT Model play a decisive role in identifying the intention of accepting new technology in male and female users. Gender differences exist because men are found to be able to adapt to a technology easily as compared to women. Three factors out of the four proposed by the UTAUT Model, i.e. performance expectancy, effort expectancy and social influence account for women's acceptance or rejection behavior largely, whereas in males, performance expectancy works the best in eliciting a positive response towards accepting a technology. Effort expectancy, social influence and facilitating conditions do not contribute significantly towards this adaptive behavior. This paper would help in addressing the gender gap in technology acceptance in an academic institute and can also pave a way towards designing gender neutral tools to facilitate women's usage of emerging technological trends. Making the ICT tools gender neutral can increase its acceptability and usage among the academic practitioners. Also, it should be noted that there is a need to study other factors for instance, trust [64]-[65]; satisfaction [66] and perceived enjoyment [67], that can contribute in bridging this gender gap not only amongst the teaching faculty but also amongst the students and the administration staff thereby making the institute a digitally functional unit where processes can be made more transparent and efficient.

\section{CONFLICT OF INTEREST}

The authors declare no conflict of interest

\section{AUTHOR CONTRIBUTIONS}

Divya Dosaya has written the Introduction and Literature Review in the study. She has conducted the data collection and also collaborated with other authors in writing the methodology, results and conclusion.

Dr. Tanu Shukla has designed the methodology of the research. She has closely supervised the questionnaire formation. She has extensively worked on data analysis and interpretation of the results. The paper was continuously edited under her guidance.

Dr. V.S. Nirban has formulated the problem statement of the study. Literature review of the existing studies was done under his guidance. He has also supervised the editing of paper throughout the process.

All the authors have approved the final version of the paper.

\section{REFERENCES}

[1] F. Webster, "The information society revisited," Handbook of New Media, 2002, pp. 255-266.

[2] B. Lundvall and S. Borrás, "The globalising learning economy: Implications for innovation policy," pp. 1-30, 1999.

[3] A. Fidani and F. Idrizi, "Investigating students' acceptance of a learning management system in university education: A structural equation modeling approach," ICT Innovations 2012 Web Proceedings, 2012, pp. 311-320.

[4] W. Ma and A. Yuen, "E-learning system acceptance and usage pattern," Technology Acceptance in Education, 2011, pp. 201-216.

[5] C. Low, Y. Chen, and M. Wu, "Understanding the determinants of cloud computing adoption," Industrial Management \& Data Systems, vol. 111, no. 7, 2011, pp. 1006-1023.

[6] V. Venkatesh, J. Y. Thong, and X. Xu, "Consumer acceptance and use of information technology: Extending the unified theory of acceptance and use of technology," MIS Quarterly, 2012, pp. 157-178.

[7] H. H. Hsu, "The acceptance of Moodle: An empirical study based on UTAUT," Creative Education, vol. 3, 2012, p. 44.

[8] R. K. Lavison, "Factors influencing the adoption of organic fertilizers in vegetable production in Accra," Doctoral dissertation, University of Ghana, 2013.

[9] J. Bonabana-Wabbi, “Assessing factors affecting adoption of agricultural technologies: The case of Integrated Pest Management (IPM) in Kumi District, Eastern Uganda," Doctoral dissertation, Virginia Tech, 2002. 
[10] M. Loevinsohn, J. Sumberg, A. Diagne, and S. Whitfield, "Under what circumstances and conditions does adoption of technology result in increased agricultural productivity?" A Systematic Review, 2013.

[11] G. Feder, R. E. Just, and D. Zilberman, "Adoption of agricultural innovations in developing countries: A survey," Economic Development and Cultural Change, vol. 33, no. 2, 1985, pp. 255-298.

[12] K. Bandyopadhyay and K. A. Fraccastoro, "The effect of culture on user acceptance of information technology," Communications of the Association for Information Systems, vol. 19, no. 1, p. 23, 2007.

[13] M. Ally and M. Gardiner, "The moderating influence of device characteristics and usage on user acceptance of smart mobile devices," in Proc. the 23rd Australasian Conference on Information Systems (ACIS 2012), pp. 1-11, 2012.

[14] C. C. Lewis et al., "Faculty use of established and emerging technologies in higher education: A unified theory of acceptance and use of technology perspective," International Journal of Higher Education, vol. 2, no. 2, pp. 22-34, 2013.

[15] V. Venkatesh, J. Y. Thong, and X. Xu, "Unified theory of acceptance and use of technology: A synthesis and the road ahead," Journal of the Association for Information Systems, vol. 17, no. 5, pp. 328-376, 2016.

[16] H. Heijden, "User acceptance of hedonic information systems," MIS Quarterly, vol. 28, pp. 695-704, 2004.

[17] I. Ajzen and M. Fishbein, "Attitude-behavior relations: A theoretical analysis and review of empirical research," Psychological Bulletin, vol. 84 , no. 5,1977 , p. 888

[18] D. Gefen, E. Karahanna, and D. W. Straub, "Trust and TAM in online shopping: An integrated model," MIS Quarterly, vol. 27, no. 1, 2003 , pp. 51-90.

[19] P. Hanafizadeh, B.W. Keating, and H. R. Khedmatgozar, "A systematic review of Internet banking adoption," Telemat. Inform, vol. 31, no. 3, 2014, pp. 492-510

[20] V. Venkatesh, M. G. Morris, G. B. Davis, and F. D. Davis, "User acceptance of information technology: Toward a unified view," MIS Quarterly, 2003, pp. 425-478

[21] S. S. Al-Gahtani, G. S. Hubona, and J. Wang, "Information technology (IT) in Saudi Arabia: culture and the acceptance and use of IT," Information \& Management, vol. 44, no. 8, 2007, pp. 681-691.

[22] A. A. Taiwo and A. G. Downe, "The theory of user acceptance and use of technology (UTAUT): a meta-analytic review of empirical findings," Journal of Theoretical \& Applied Information Technology, vol. 49, no. 1, 2013, pp. 48-58.

[23] B. Kaba and B. Touré, "Understanding information and communication technology behavioral intention to use: Applying the UTAUT model to social networking site adoption by young people in a least developed country," Journal of the Association for Information Science \& Technology, vol. 65, no. 8, 2014, pp. 1662-1674.

[24] C. M. Chiu and E. T. Wang, "Understanding Web-based learning continuance intention: the role of subjective task value," Information \& Management, vol. 45, no. 3, 2008, pp. 194-201.

[25] M. S. Diño and A. B. Guzman, "Using partial least squares (PLS) in predicting behavioral intention for telehealth use among Filipino elderly," Educational Gerontology, vol. 41, no. 1, 2015, pp. 53-68.

[26] Y. S., Wang and Y. W. Shih, "Why do people use information kiosks? A validation of the Unified Theory of Acceptance and Use of Technology," Government Information Quarterly, vol. 26, no. 1, 2009, pp. $158-165$

[27] C. P. Lin and B. Anol, "Learning online social support: an investigation of network information technology based on UTAUT," Cyber Psychology\& Behavior, vol. 11, no. 3, 2008, pp. 268-272

[28] Z. Zaremohzzabieh, B. A. Samah, S. Z. Omar, J. Bolong, and H. A. M. Shaffril, "Fisherman's acceptance of information and communication technology integration in Malaysia: Exploring the moderating effect of age and experience," Journal of Applied Sciences, vol. 14, no. 9, 2014, pp. $873-882$

[29] C. K. Hou, "Exploring the user acceptance of business intelligence systems in Taiwan's electronics industry: applying the UTAUT model," International Journal of Internet and Enterprise Management, vol. 8, no. 3, 2014, pp. 195-226.

[30] V. Venkatesh, M. G. Morris, G. B. Davis, and F. D. Davis, "User acceptance of information technology: Toward a unified view," MIS Quarterly, 2003, pp. 425-478

[31] B. Šumak and A. Šorgo, "The acceptance and use of interactive whiteboards among teachers: Differences in UTAUT determinants between pre-and post-adopters," Comput. Hum. Behav., vol. 64, 2016, pp. 602-620.

[32] B. Šumak, M. Pušnik, M. Herièko, and A. Šorgo, "Differences between prospective, existing, and former users of interactive whiteboards on external factors affecting their adoption, usage and abandonment," Comput. Hum. Behav., vol. 72, 2017, pp. 733-756.

[33] C. M. Chao, "Factors determining the behavioral intention to use mobile learning: An application and extension of the UTAUT model," Frontiers in psychology, no. 10, 2019, p. 1652.

[34] H. J. Kim, J. M. Lee, and J. Y. Rha, "Understanding the role of user resistance on mobile learning usage among university students," Comput. Educ., vol. 113, 2017, pp. 108-118.

[35] H. Hamidi and A. Chavoshi, "Analysis of the essential factors for the adoption of mobile learning in higher education: a case study of students of the university of technology," Telematics Inform, vol. 35 , 2018, pp. 1053-1070.

[36] S. A. Nikou and A. A. Economides, "Mobile-based assessment Investigating the factors that influence behavioral intention to use," Comput. Educ., vol. 109, 2017, pp. 56-73.

[37] L. Briz-Ponce, A. Pereira, L. Carvalho, J. A. Juanes-Méndez, and F. J. García-Peñalvo, "Learning with mobile technologies-students' behavior," Comput. Hum. Behav., vol. 72, 2017, pp. 612-620.

[38] B. H. Sheppard, J. Hartwick, and P. R. Warshaw, "The theory of reasoned action: A meta-analysis of past research with recommendations for modifications and future research," J. Consum. Res., vol. 15, no. 325, 1988.

[39] G. Rose and D. Straub, "Predicting general IT use: Applying TAM to the Arabic world," Journal of Global Information Management (JGIM), vol. 6, no. 3, pp. 39-46, 1998.

[40] M. Horst, M. Kuttschreuter, and J. M. Gutteling, "Perceived usefulness, personal experiences, risk perception and trust as determinants of adoption of e-government services in The Netherlands," Computers in Human Behavior, vol. 23, no. 4, pp. 1838-1852, 2007.

[41] O. F. El-Gayar and M. Moran, "College students' acceptance of Tablet PCs: An application of the UTAUT Model," Dakota State University, no. 820 , pp. $2845-2850,2006$.

[42] J. Brinkerhoff, "Effects of a long-duration, professional development academy on technology skills, computer self-efficacy, and technology integration beliefs and practices," Journal of Research on Technology in Education, vol. 39, no. 1, pp. 22-43, 2006.

[43] Y. Chin-Cheh et al., "The study of the management competence gap analysis: Top and middle managers of Taipei 101," Journal of Modern Accounting and Auditing, vol. 7, no. 10, p. 1122, 2011.

[44] S. S. Liaw and H. M. Huang, "Exploring the World Wide Web for online learning: A perspective from Taiwan," Educational Technology, vol. 43, no. 3, pp. 27-32, 2003.

[45] A. Vishwanath and G. M. Goldhaber, "An examination of the factors contributing to adoption decisions among late-diffused technology products," New Media \& Society, vol. 5, no. 4, pp. 547-572, 2003.

[46] V. Krishnaraju, S. K. Mathew, and V. Sugumaran, "Web personalization for user acceptance of technology: An empirical investigation of e-government services," Information Systems Frontiers, vol. 18, no. 3, pp. 579-595, 2016.

[47] A. Raman and Y. Don, "Preservice teachers' acceptance of learning management software: An application of the UTAUT2 model," International Education Studies, vol. 6, no. 7, pp. 157-164, 2013.

[48] T. Dinev, Q. Hu, and J. Goo, "User behavior toward preventive technologies - Examining cross-cultural differences between the United states and South Korea," in Proc. the 13th Annual Cross-Cultural Research in Information Systems Conference (CCRIS), Las Vegas, USA, 2005.

[49] E. Mao and P. Palvia, "The effect of culture on information technology acceptance," in Proc. the 32nd Annual Meeting of Decision Sciences Institute, San Francisco, CA, 2001.

[50] S. Al-Shafi, V. Weerakkody, and M. Janssen, "Investigating the adoption of egovernment services in Qatar using the UTAUT model," AMCIS 2009 Proceedings, p. 260, 2009.

[51] M. Fishbein and I. Ajzen, "Belief, attitude, intention and behavior: An introduction to theory and research Addison-Wesley," Reading, 1975.

[52] C. Nanayakkara, "A model of user acceptance of learning management systems: A study within tertiary institutions in New Zealand," The International Journal of Learning, vol. 13, no. 12, pp. 223-232, 2007.

[53] F. Deng et al., "The relationships among Chinese practicing teachers' epistemic beliefs, pedagogical beliefs and their beliefs about the use of ICT," Journal of Educational Technology \& Society, vol. 17, no. 2, pp. 245-256, 2014.

[54] Y. Liu and H. Wang, "A comparative study on e-learning technologies and products: from the East to the West," Systems Research and Behavioral Science: The Official Journal of the International Federation for Systems Research, vol. 26, no. 2, pp. 191-209, 2009.

[55] S. Mumtaz, "Factors affecting teachers' use of information and communications technology: a review of the literature," Journal of 
Information Technology for Teacher Education, vol. 9, no. 3, pp. 319-342, 2000

[56] F. D. Davis, R. P. Bagozzi, and P. R. Warshaw, "User acceptance of computer technology: a comparison of two theoretical models," Manag. Sci., vol. 35, 1989, pp. 982-1003.

[57] F. D. Davis, "Perceived usefulness, perceived ease of use, and use acceptance of information technology," MIS Q., vol. 13, 1989, p. 319.

[58] R. P. Bagozzi et al., Manag. Sci., 1989.

[59] V. Venkatesh and F. D. Davis, "A theoretical extension of the technology acceptance model: four longitudinal field studies," Manag. Sci., vol. 46, 2000, pp. 186-204.

[60] I. Ajzen, "The theory of planned behavior," Organ. Behav. Hum. Decis. Process, vol. 50, 1991, pp. 179-211.

[61] A. I. Pramanik and M. N. Islam, "Technology tools and approaches to improve undergraduate education," Int J Res Educ Methodol, vol. 4, no. 1, pp. 390-400, 2013.

[62] B. Šumak, G. Polancic, and M. Hericko, "An empirical study of virtual learning environment adoption using UTAUT," in Proc. 2010 Second International Conference on Mobile, Hybrid, and on-Line Learning, pp. 17-22, 2010.

[63] S. Taylor and P. A. Todd, "Understanding information technology usage: a test of competing models," Inf. Syst. Res., vol. 6, 1995, pp. $144-176$

[64] R. L. Thompson, C. A. Higgins, and J. M. Howell, "Personal computing: toward a conceptual model of utilization,” MIS Q., vol. 15, 1991, pp. $125-143$.

[65] R. J. Vallerand, "Toward a hierarchical model of intrinsic and extrinsic motivation," Advances in Experimental Social Psychology, 1997, pp. 271-360.

[66] A. Bandura, Social Foundations of Thought and Action: A Social Cognitive Theory. Englewood Cliffs, NJ: Prentice-Hall. 1986.

[67] D. R. Compeau and C. A. Higgins, "Computer self-efficacy: Development of a measure and initial test," MIS Q., vol. 19, 1995, pp. 189-211.
Copyright $(\odot 2020$ by the authors. This is an open access article distributed under the Creative Commons Attribution License which permits unrestricted use, distribution, and reproduction in any medium, provided the original work is properly cited (CC BY 4.0).

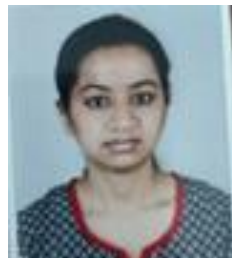

Divya Dosaya is a doctoral student at the Department of Humanities and Social Sciences, BITS Pilani, India. She pursued her master's in forensic psychology and is working on teacher professional development, student achievement and secondary education

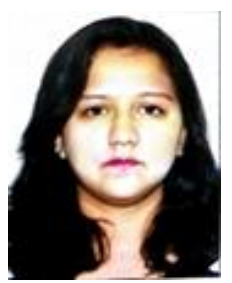

Tanu Shukla is an assistant professor at BITS Pilani, India. She pursued her Ph.D. in educational policy, planning and administration from NIEPA, New Delhi. She has 7 years of teaching experience and 12 years of research experience in educational planning and administration. She works in the area of education, applied psychology, research methods and organizational behavior.

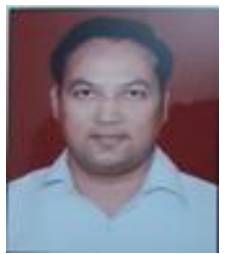

Virendra Singh Nirban is an associate professor a BITS Pilani. He pursued his Ph.D. in technology and education from BITS Pilani, India. He has 10 years of research experience in the area of technology interventions in education and e-governance, computer-mediated discourse analysis and social media studies. 